WellBeing International

WBI Studies Repository

2-2009

\title{
Effect of Noxious Stimulation Upon Antipredator Responses and Dominance Status in Rainbow Trout
}

\author{
Paul J. Ashley \\ University of Liverpool \\ Sian Ringrose \\ University of Liverpool \\ Katie L. Edwards \\ University of Liverpool \\ Emma Wallington \\ University of Liverpool \\ Catherine R. McCrohan \\ University of Manchester
}

See next page for additional authors

Follow this and additional works at: https://www.wellbeingintlstudiesrepository.org/acwp_aff

Part of the Animal Studies Commons, Other Animal Sciences Commons, and the Veterinary

Physiology Commons

\section{Recommended Citation}

Ashley, P. J., Ringrose, S., Edwards, K. L., Wallington, E., McCrohan, C. R., \& Sneddon, L. U. (2009). Effect of noxious stimulation upon antipredator responses and dominance status in rainbow trout. Animal Behaviour, 77(2), 403-410.

This material is brought to you for free and open access by WellBeing International. It has been accepted for inclusion by an authorized administrator of the WBI Studies Repository. For more information, please contact wbisr-info@wellbeingintl.org.

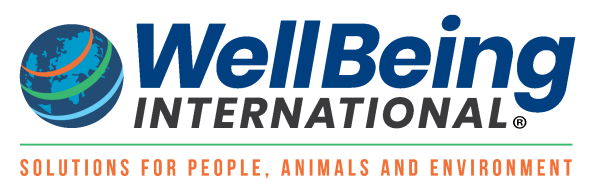




\section{Authors}

Paul J. Ashley, Sian Ringrose, Katie L. Edwards, Emma Wallington, Catherine R. McCrohan, and Lynne U. Sneddon 


\title{
Effect of Noxious Stimulation Upon Antipredator Responses and Dominance Status in Rainbow Trout
}

\author{
Paul J. Ashley ${ }^{1}$, Sian Ringrose ${ }^{1}$, Katie L. Edwards ${ }^{1}$, Emma Wallington ${ }^{1}$, Catherine R. McCrohan ${ }^{2}$, Lynne \\ U. Sneddon ${ }^{1}$ \\ ${ }^{1}$ University of Liverpool \\ ${ }^{2}$ University of Manchester
}

\section{KEYWORDS}

Antipredator, dominance status, nociception, Oncorhynchus mykiss, pain, rainbow trout

\begin{abstract}
A potentially painful experience may modify normal behavioural responses. To gauge the importance of pain relative to predation or social status, we presented competing stimuli, a predator cue or an unfamiliar social group, to two groups of noxiously treated rainbow trout, Oncorhynchus mykiss. In the predator cue experiment, fish were classified as bold or shy. Noxiously stimulated fish did not show antipredator responses, suggesting that pain is the imperative. In the social status experiment, noxiously stimulated fish held individually and undisturbed showed an increase in respiration rate and plasma cortisol. As a comparison, we used the dominant or subordinate fish in a group as the noxiously stimulated fish. After the noxious treatment, we returned this test fish to a familiar or unfamiliar social group. Neither dominants nor subordinates showed a negative change in physiology compared to their controls. However, in a familiar group the dominant was much less aggressive, suggesting a behavioural impairment in response to noxious stimulation. In an unfamiliar group, no reduction of aggression was seen, suggesting that maintaining dominance status took priority over showing signs of pain. These findings may reflect an ability to prioritize motivational drivers in fish, and as such provides evidence for central processing of pain rather than merely showing a nociceptive reflex.
\end{abstract}

In animal models of pain, exposure to a new circumstance or a potentially fear-inducing or stressful situation reduces pain reactivity (e.g. Lester \& Fanselow 1985; Harris \& Westbrook 1994; Kavaliers \& Colwell 1994; Gentle \& Corr 1995; Gentle \& Tilston 1999; Del Seppia et al. 2003; Nakama-Kitamura \& Doe 2003; Smith et al. 2003). For example, chickens, Gallus gallus domesticus, with gouty arthritis exposed to a novel environment showed a reduction in their pain-related responses including the severity of inflammation in the affected joint (Gentle \& Corr 1995; Gentle \& Tilston 1999). Rodents exposed to predator odour also show reduced behavioural responses to pain, and anxiety tests have the same effect (Lester \& Fanselow 1985; Kavaliers \& Colwell 1991; Nakama-Kitamura \& Doe 2003; Geerse et al. 2006). In humans, pain takes priority when it is chronic or particularly intense, and concurrent tasks are poorly performed (Kuhajda et al. 2002). Therefore, if pain is a high priority, it will affect behavioural responses to other stimuli (Eccleston 1995; Moseley \& Arntz 2007). 
These studies suggest that measuring the responses to competing stimuli during a painful event could be exploited as a tool to determine the relative importance of pain or nociception to an animal. Direct assessment of pain in animals is impossible owing to its subjective nature. However, many studies have identified behavioural and physiological responses to a potentially painful event in a variety of animals including fish (Sneddon et al. 2003a), amphibians (Willenbring \& Stevens 1995), birds (Machin 2005) and mammals (Flecknell \& Roughan 2004). Pain in animals is a contentious issue, especially for the coldblooded vertebrates because of differences in their neurobiology from that of higher vertebrates (Chandroo et al. 2004). However, nociceptors have been identified in fish and these are similar to those found in mammals (Sneddon 2002, 2003a; Sneddon et al. 2003a; Ashley et al. 2006, 2007). Moreover, studies have shown that the brain of the fish is active during noxious stimulation and that this activity differs from the response to neutral stimuli (Dunlop \& Laming 2005; Reilly et al. 2008a). Negative changes in behaviour and physiology have also been recorded (Sneddon et al. 2003a, b), suggesting an aversive affective state, and these are reduced by administering an analgesic (Sneddon 2003b). However, the real significance of this experience to the fish has not been explored. We tested this by providing noxiously stimulated rainbow trout, Oncorhynchus mykiss, with one of two different contexts to examine whether pain is the imperative. One context was the presentation of an antipredator cue to gauge responses to this threatening stimulus and the other was social novelty where fish were placed into an unfamiliar social situation.

Previous work demonstrated that noxiously stimulated fish do not show the classic neophobia when a fear-inducing stimulus, a novel object, is introduced (Sneddon et al. 2003b), indicating that pain dominates their attention in this context. However, it is possible that the novel objects used in that study were not sufficiently threatening to divert the fish' $s$ attention. In this study, we used more ecologically relevant and important distractors such as predation and social groupings to test the relative importance of noxious stimulation in these scenarios.

Avoiding being eaten by predators is a strong motivational drive for all prey animals and is, therefore, likely to be a strong stimulus to use as a competing stimulus. Fish are very sensitive to the presence of predators and predator-naïve fish show antipredator behaviours if they are given the odour of a predator in combination with the odour obtained from a damaged prey fish (Mirza \& Chivers 2003; Zhao et al. 2006). This latter odour is called alarm substance or pheromone and is produced by damaged fish skin to elicit antipredator responses in conspecifics (Brown 2003; Scott et al. 2003). Antipredator behaviour can consist of freezing where the fish remains motionless, erratic escape swimming, increased refuge or cover use, sinking and spending more time in the bottom of the tank and a reduction in feeding attempts (Scheurer et al. 2007). Because these behaviours assist in avoiding detection, we used an antipredator cue to determine whether noxiously stimulated fish perform appropriate antipredator behaviour.

Rainbow trout are territorial and naturally form dominance hierarchies, usually including a bold individual that restricts the behaviour of subordinates (Sneddon et al. 2005). Individuals of lower status have higher stress levels as a result of losing contests with the dominant and have reduced access to food (Gilmour et al. 2005). Therefore, dominance status influences the probability of survival and overall fitness. As such, maintaining status is likely to be an important motivational driver in the behaviour of this species. We tested the behavioural and physiological responses of the top-ranked fish (dominant) and the lowestranked fish (subordinate) in a group to determine whether they show signs of pain or nociception when held in familiar groups where their dominance is already established. This was compared to returning the noxiously stimulated fish to unfamiliar groups where their dominance had not been established.

Behavioural analysis of large groups can be confounded by individual variation linked to boldness and this can affect responses to noxious stimulation (L. U. Sneddon, K. L. Edwards, S. Ringrose, L. J. Ashley 
\& C. R. McCrohan, unpublished data). Rainbow trout can be either bold and aggressive or shy and timid, as reflected in their behaviour (Sneddon 2003c; Frost et al. 2007). Bold fish tend to take more risks, are more active, spend more time in open water, learn conditioning tasks faster and dominate shy fish (Sneddon 2003c; Frost et al. 2007). Therefore, we first determined the degree of boldness of our experimental subjects to investigate whether the response to noxious stimulation was affected by the 'personality' of the fish. We hypothesized that bold fish may be more likely to recover from a noxious event and respond to concurrent stimuli, such as exploring a new environment.

We also hypothesized that, if a potentially painful stimulus is important to the fish, noxiously stimulated fish will not respond in an appropriate manner to a predator cue. This may also be affected by the degree of boldness of the fish whereby bold fish may show more risk-prone behaviours during the presentation of the predator cue than shy fish. Finally, we tested the hypothesis that noxiously stimulated fish held in social groups may appear less affected by pain than individually held fish as they need to maintain their social status.

\section{METHODS}

\section{Experiment 1: Predator Cue}

\section{Husbandry and set-up}

Twenty-four juvenile rainbow trout (mean weight $\pm S E=45 \pm 2 \mathrm{~g}$ ) were caught at random from a stock tank ( $2 \times 2 \mathrm{~m}$ and $0.5 \mathrm{~m}$ high; $\mathrm{N}=100$ of original stock), transferred to individual experimental tanks ( $45 \mathrm{x}$ $30 \mathrm{~cm}$ and $40 \mathrm{~cm}$ high) and left for 7 days to acclimate in a 12:12 h light:dark regime. Each tank had a constant flow of filtered freshwater at a temperature of $11 \pm 1{ }^{\circ} \mathrm{C}$, a gravel substrate and a refuge pipe (opaque plastic, $8 \mathrm{~cm}$ long $\times 8 \mathrm{~cm}$ in diameter). Half of the top of the tank had an opaque plastic cover (15 $\mathrm{cm} \times 30 \mathrm{~cm}$ ) to provide an area of shelter; the other half was left open. The cover was positioned on top of the tank ( $5 \mathrm{~cm}$ from the water surface as an overhang, so the fish could swim freely at the surface). The sides and backs of the tanks were covered in black plastic to isolate the fish visually and socially and to prevent any disturbance. A large screen with small openings for observation was placed in front of the tanks. The water was continuously aerated and fish were fed daily with their normal diet, commercial pellets (Skretting, Northwich, U.K.), at the recommended rate of $1 \%$ body weight per day. Prior to experiments the flow-through system was turned off so that water in each tank was contained. At the end of each experiment the tanks were thoroughly cleaned.

\section{Experimental protocol}

Fish were randomly assigned to one of four groups: control shy, control bold, acid treatment (noxious stimulation) shy and acid treatment bold. After acclimation to their new environment, the fish were tested for boldness using the novel object test (Wilson et al. 1993; Frost et al. 2007). Low-light-level cameras were set-up at the front and at the side of the tank to give 3D positioning, and rulers were positioned horizontally and vertically along the front and side of the tank to measure the distance from the object. We used a video recorder and monitor outside the experimental room including a video inset system which places one picture within another to allow both images to be viewed simultaneously. The behaviour was scored using custom-written behavioural analysis software on a PC. After the cameras were set-up, we left the fish overnight to recover from the disturbance. The next morning they were recorded for $10 \mathrm{~min}$ to obtain a baseline level of 'norma' behaviour, and then a novel object (constructed from a variety of white, black, yellow and green Lego bricks; dimensions $10 \times 15 \times 5 \mathrm{~cm}$ ) was added and left for a further $10 \mathrm{~min}$. If a fish approached the novel object within $5 \mathrm{~cm}$ in the first 2 min it was deemed bold; if a fish did not approach the novel object within $10 \mathrm{~min}$ it was deemed shy. The experiment was conducted the following day. 
The following procedures were conducted by experienced personnel (L.S. and P.A.) licensed by the U.K. Home Office. For the control groups, fish were individually removed from their tank and placed in a 25litre bucket with 10 litres of anaesthetic-dosed water $(1 \mathrm{ml} /$ litre of a $300 \mathrm{mg}$ benzocaine in $9 \mathrm{ml}$ of ethanol). Once deep anaesthesia was reached (no reflex response to tail press), the fish was carefully removed from the bucket, placed on a wet paper towel and injected ( $25 \mathrm{~g}$ needle and $1 \mathrm{ml}$ syringe) with $0.1 \mathrm{ml}$ of sterile saline into the upper and lower frontal lips. This procedure took less than $2 \mathrm{~min}$. The fish was then returned to its tank and allowed a 30 min recovery period from the anaesthesia and handling. The acid-treated fish were treated as above but were injected in the frontal lips with $0.1 \mathrm{ml}$ of acetic acid ( $0.1 \%$ in sterile saline). Acetic acid has been shown to activate nociceptors (Hamamoto et al. 2000; Ashley et al. 2007).

Prior to injection, we observed the fish for 15 min to record normal behaviour for the entire period and respiration rate at intervals during the period. Respiration rate was the number of opercular (gill) beats/min or opercular beat rate (OBR) and was measured at 4 min intervals to give an average for each 15 min recording period. Behaviours recorded were cover use (time spent in the half of the tank under the overhanging cover), the frequency of swimming more than one body length, and the percentage time spent active (engaged in any behaviours other than being passive or motionless) in both the open and covered areas.

After the injection, the OBR and behavioural measures were recorded again for $15 \mathrm{~min}$. The fish were then exposed to $20 \mathrm{ml}$ of alarm pheromone (using a $50 \mathrm{ml}$ syringe and air tubing) added to the tank at the back corner at the end of the open area. To obtain pheromone extract, nine fish from the same stock were killed by concussion followed by exsanguination; they were then skinned and the skin was rinsed with deionized water. The skin $(X \pm S E=4: 1 \pm 0: 35 \mathrm{~g})$ was then cut with a razor to damage the cells and placed into $50 \mathrm{ml}$ tubes containing $25-30 \mathrm{ml}$ of deionized, sterile water kept chilled on ice. The skin-water mixture was then homogenized and centrifuged for $15 \mathrm{~min}$ at $8000 \mathrm{rpm}$ at $4{ }^{\circ} \mathrm{C}$. The supernatant was extracted, filtered to remove debris and placed in a clean $50 \mathrm{ml}$ tube and then frozen at $-20{ }^{\circ} \mathrm{C}$. After defrosting the sample, we made it up to $200 \mathrm{ml}$ using deionized, sterile water and kept it on ice before use.

Observations of $15 \mathrm{~min}$ periods continued for $3 \mathrm{~h}$ at $30 \mathrm{~min}$ intervals after we added the alarm pheromone; $3 \mathrm{~h}$ is the time taken for acid-injected fish to show full recovery (Sneddon 2003b). At the end of the experiment, fish were caught by net and immediately killed humanely by concussion followed by brain destruction, and blood samples were taken for cortisol analysis via caudal veinipuncture using a 25 $\mathrm{g}$ needle and $2 \mathrm{ml}$ syringe. The stress of capture could affect cortisol levels; however, all fish were killed within $5 \mathrm{~s}$ and treated identically to make the samples comparable. The blood was kept chilled on ice in Eppendorf tubes and centrifuged at $3500 \mathrm{~g}$ for $5 \mathrm{~min}$ at $4{ }^{\circ} \mathrm{C}$. The supernatant containing the plasma was placed in a fresh tube and stored at $-20{ }^{\circ} \mathrm{C}$. Validated cortisol radioimmunoassays were performed blind by an external laboratory (Pickering et al. 1987).

\section{Statistical analyses}

Each group, control bold, control shy, acid bold and acid shy, comprised six fish. We used Kruskal-Wallis tests to determine the effects of group on the percentage time active and cover use duration, followed by a Fisher's exact test. The percentage change in time spent active, duration of time spent under cover and respiration rate after presentation of the alarm pheromone for the four groups were compared using a Kruskal-Wallis test followed by a Fisher's exact test. The frequency of approaches to the location where the alarm pheromonewas introduced, cortisol levels and the OBR were all normally distributed so we used two-way ANOVAs followed by Tukey highly significant difference (HSD) tests to analyse effects of 
treatment and boldness. All statistics were carried out with MINITAB (Minitab Inc., State Collage, PA, U.S.A.) using two-tailed tests throughout and adjusting $P$ values for multiple testing.

\section{Experiment 2: Novel Social Group}

In this experiment, boldness was not assessed since it has been established that bold fish dominate shy fish (Frost et al. 2007) and so by selecting the dominant and subordinate, we chose the boldest and shyest fish within the groups. We held fish as previously described but in this experiment all tanks were barren, except for two plastic tubes (length $15 \mathrm{~cm}$, diameter $10 \mathrm{~cm}$ ) provided as a refuge allowing subordinates to avoid the dominant fish. Groups $(N=24)$ of three size-matched fish were caught randomly, and we noted identifying characteristics such as colour, fin shape and size to differentiate between fish. The dominance hierarchy in each tank was assessed during a 1-week acclimatization period by recording the frequency of aggressive strikes, that is, a direct movement from one fish to another, and the frequency of retreats, where one fish moved more than one body length away from a strike. The number of retreats was subtracted from the number of strikes each individual performed and the fish with the largest number was deemed to be dominant. In this experimental set-up, no direct contact was made during strikes, presumably because of the presence of refuges and the significant distance to which the fish could retreat, and no injuries were sustained. The fish with the smallest number was the subordinate. These individuals acted as the test fish as described below. As stressed fish tend to be anorexic (Hoglund et al. 2007), fish were offered food daily until they resumed feeding, at which point they were considered settled.

At the start of the experiment, we recorded the normal behavior of the fish for a 30 min baseline period. The position of the fish in the tank, the use of cover and the activity levels were all monitored along with the OBR. The fish to be treated, either the dominant or subordinate, was then removed from the tank and anaesthetized. It was weighed and treated with either $0.1 \%$ acetic acid or sterile saline as described above. The fish was then placed in a bucket of aerated freshwater for $10 \mathrm{~min}$ to recover before being returned to its own experimental tank or to an unfamiliar tank from which either the established dominant or subordinate had already been removed.

Similar behaviours were monitored as before in addition to any interactions (strikes and retreats). Observations were made in this way for $15 \mathrm{~min}$, every $30 \mathrm{~min}$, until $3 \mathrm{~h}$ after the injection. The test fish was caught by net and then humanely killed immediately (within $5 \mathrm{~s}$ ) by concussion followed by brain destruction and blood samples were taken for cortisol analysis. For comparison, a set of six salineinjected and six acid-injected fish were held individually for $3 \mathrm{~h}$ to allowcomparison of the physiological data (OBR and cortisol) with the group-held fish.

\section{Statistical analyses}

We used two-way ANOVA (post hoc tests: Tukey HSD) to test the effects of treatment and time on OBR in individual, dominant and subordinate test groups. Striking was converted to a rate (per min) and ANOVA was used to determine the difference between control and treatment in the dominant groups returned to familiar or unfamiliar tanks. Cortisol levels were analysed using two-sample t-tests to examine differences between control and treatment in each group and ANOVA was used to test between individually held groups and dominant or subordinate groups. All statistics were carried out with MINITAB using two-tailed tests throughout and adjusting $\mathrm{P}$ values for multiple testing.

\section{Ethical Note}

This research was approved by the University of Liverpool Ethics Committee and conducted humanely under a Project Licence of the U.K. Home Office. The question of pain in fish is subject to debate and is 
currently unresolved; therefore, this study provides new information that may inform improvements in fish welfare. We kept sample sizes to a minimum based on previously published work and stopped the experiments when significance had been obtained $(P<0.05)$ in at least two of the behavioural measures. We used farmed fish which are bred for food and restocking programmes. The fish were fed their normal diet obtained from the fish farm at the recommended rate of $1 \%$ body weight per day. Since pain or nociception is such a strong stimulus, equally strong stimuli were used to try to divert attention away from the noxious event. These were biologically relevant since rainbow trout naturally form dominance hierarchies in nature and under captive conditions (Gilmour et al. 2005). Therefore, it is important to understand what effects social housing has on the responses to pain since, previously, all measures have been conducted in solitary fish (Sneddon 2003b; Sneddon et al. 2003a, b; Reilly et al. 2008a, b). Two refuges were present in the dominance tests so that the lower-ranked fish could actively avoid the dominant and decide to engage in or withdraw from social interactions. Food was provided in abundance and all pellets were added at once, sprinkled over the whole of the tank so that the food could not be monopolized; all fish were observed to eat. None of these fish showed any adverse effects of this social housing. In experiment 1 , only the chemical cue of predator threat was present and a refuge was provided so that the fish could hide.

\section{RESULTS}

\section{Experiment 1: Predator Cue}

After the addition of alarm pheromone, the percentage change in time spent being active in the entire tank was significantly affected by both the treatment and the boldness of the fish $\left(\mathrm{H}_{3}=15.9, \mathrm{P}<0.001\right.$; Fisher's exact test: $P=0.02$; Fig. 1a). Overall, being active increased after addition of alarm pheromone. Control bold fish increased the time spent active from $28 \%$ to $56 \%$ and control shy fish also increased their activity from $16 \%$ to $48 \%$. However, the noxiously stimulated fish did not increase their activity as a result of alarm pheromone addition (Fig. 1a); activity in these fish was lower than controls (bold acid increasing from $27 \%$ to $38 \%$ and shy acid from $15 \%$ to $17 \%$ ).

The change in the amount of time spent under the covered half of the tank (cover use), in response to addition of the alarm pheromone, was significantly affected by both the treatment and boldness $\left(\mathrm{H}_{3}=\right.$ 14.2, $N=24, \mathrm{P}<0.001$; Fisher's exact test: $\mathrm{P}=0.02$; Fig. $1 \mathrm{~b})$. In the control group, there was no difference between bold and shy fish in their response to alarm pheromone, with bold fish increasing cover use from $299 \mathrm{~s}$ to $524 \mathrm{~s}$; shy controls similarly showed an increase from $360 \mathrm{~s}$ to $575 \mathrm{~s}$. Bold and shy fish in the noxiously treated group showed differential responses to the pheromone: the bold acid fish reduced cover use from a median of $362 \mathrm{~s}$ to $250 \mathrm{~s}$, whereas shy acid fish showed no significant change (570 s to $636 \mathrm{~s}$ ).

Acid-treated fish showed less swimming activity overall than the control group. However, there was no effect of either treatment or boldness on the response to alarm pheromone $\left(H_{3}=1.17, P=0.65\right.$; Fisher's exact test: $P=0.77$ ).

Neither treatment nor boldness had an effect on the OBR after the alarm pheromone was added (treatment: $F_{1,20}=0.82, P=0.376$; boldness: $F_{1,20}=0.04, P=0.842$; interaction: $F_{1,20}=0.38, P=0.544$; bold and shy comparison: Tukey HSD: $P=0.01$; Fig. 1c). The time course analysis (Fig. 1C) indicates that, after the injection, the acid-treated group showed an initial rapid increase in OBR; this was maintained with a slight decrease over time demonstrating recovery from the noxious stimulation. The control group showed a gradual rise in OBR over time following exposure to the alarm pheromone. 
Plasma cortisol level, measured at the end of the experiment, was not affected by either treatment (control: mean $\pm \mathrm{SE}=103.8 \pm 12.2 \mathrm{ng} / \mathrm{ml}$; acid: $120.8 \pm 13.5 \mathrm{ng} / \mathrm{ml} ; \mathrm{F}_{1,20}=0.82, \mathrm{P}=0.377$ ) or boldness $\left(F_{1,20}=0.24, P=0.633\right)$ and with no interaction between the two factors $\left(F_{1,20}=0.11, P=0.743\right)$.

Figure 1. (a) The median (interquartiles) change in percentage time spent active in bold and shy fish injected with either saline (control) or acid (acid) from before to after the addition of alarm pheromone. (b) The median change in duration of time spent under cover by bold and shy fish in the control and acid groups from before to after the addition of alarm substance. (c) The mean \pm SE opercular beat rate (OBR) in control and acid-injected fish (acid) over the experimental period from normal preinjection values (BT), before the addition of alarm substance (BS) and in the subsequent observations (AS1-AS6). ${ }^{*} P<0.01 . N=24$.
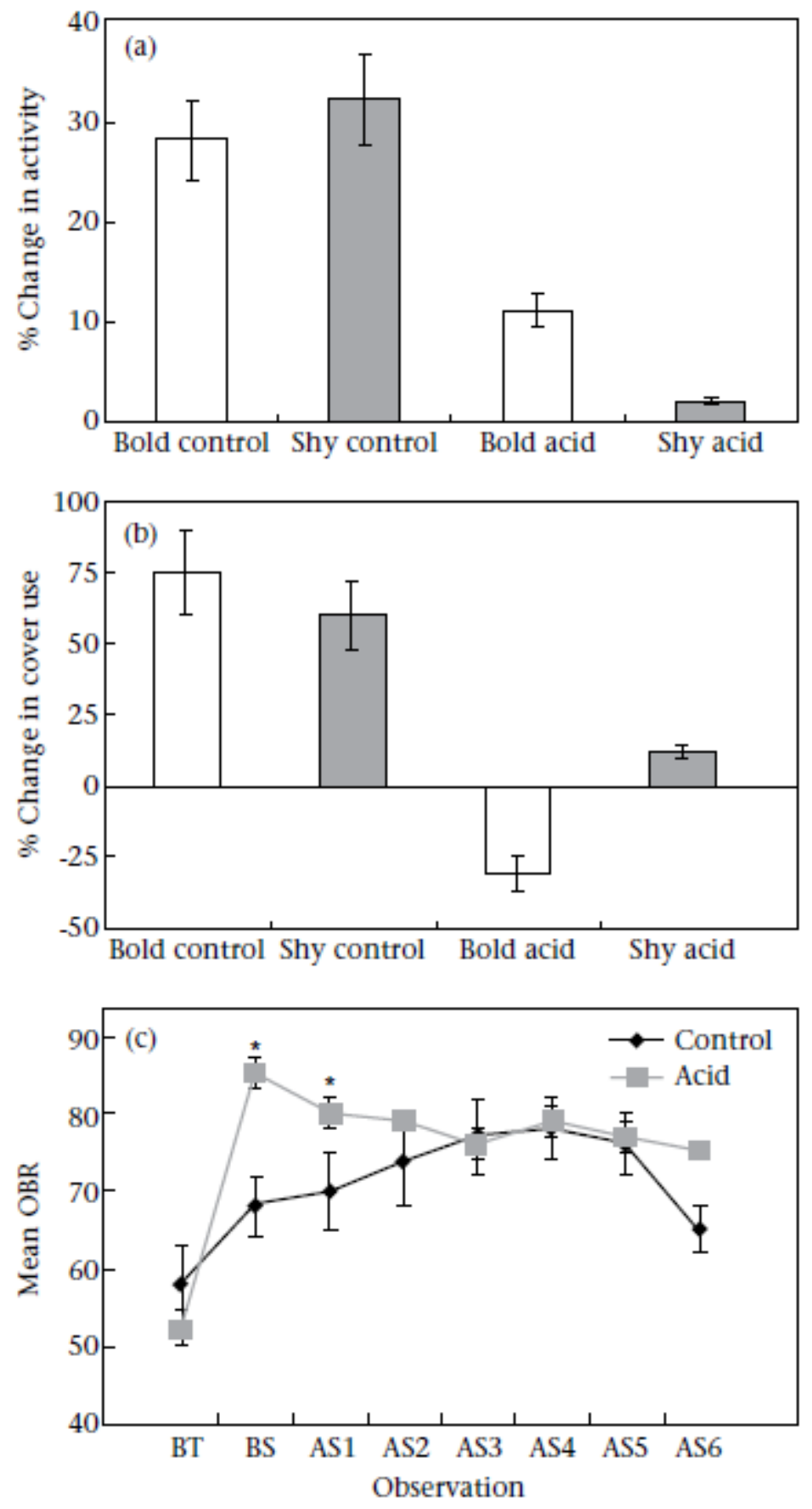


\section{Experiment 2: Novel Social Group}

The respiration rate of all fish increased following injection. In individually held fish, OBR was significantly higher in noxiously stimulated individuals than in saline injected controls $\left(F_{1,10}=28.70, P<0.001\right.$; Fig. $\left.2 a\right)$ and both groups showed a decrease over time indicating recovery $\left(F_{6,60}=25.78, P<0.001\right.$; interaction of treatment ${ }^{\star}$ time: $F_{6,60}=7.47, \mathrm{P}<0.001$ ). In dominant fish returned to either a familiar or unfamiliar social situation, there was no difference between control and treatment OBR (familiar: $F_{1,10}=0.45, P=0.520$; unfamiliar: $F_{1,10}=0.12 ; P=0.740$ ) but both groups demonstrated recovery (familiar: $F_{6,60}=4.39, P=$ 0.010; unfamiliar: $F_{6,60}=7.01, P<0.001$; Fig. $2 b$ ). Similarly, when the subordinate was the test fish, there was no difference between control and treatment $\left(F_{1,10}=1.57, P=0.239\right)$ or between familiar or unfamiliar social groups $\left(F_{6,36}=0.94, P=0.489\right.$ : Tukey HSD: $\left.P=0.785\right)$. Again there was a reduction of OBR over time for both familiar $\left(F_{6,36}=4.65, P=0.001\right)$ and unfamiliar social groups $\left(F_{6,36}=4.68, P=0.001\right.$; Fig. 2c).

Figure 2. The effects of (a) being held individually, (b) being dominant and placed in a familiar or unfamiliar social group and (c) being subordinate and placed in a familiar or unfamiliar social group on opercular beat rate (OBR) after injection of saline (control) or acid. The data are plotted over the experimental period at time 0 before injection and at subsequent intervals after injection. ${ }^{*} \mathrm{P}<$ 0.001. (a) $N=12$, (b, c) $N=24$.
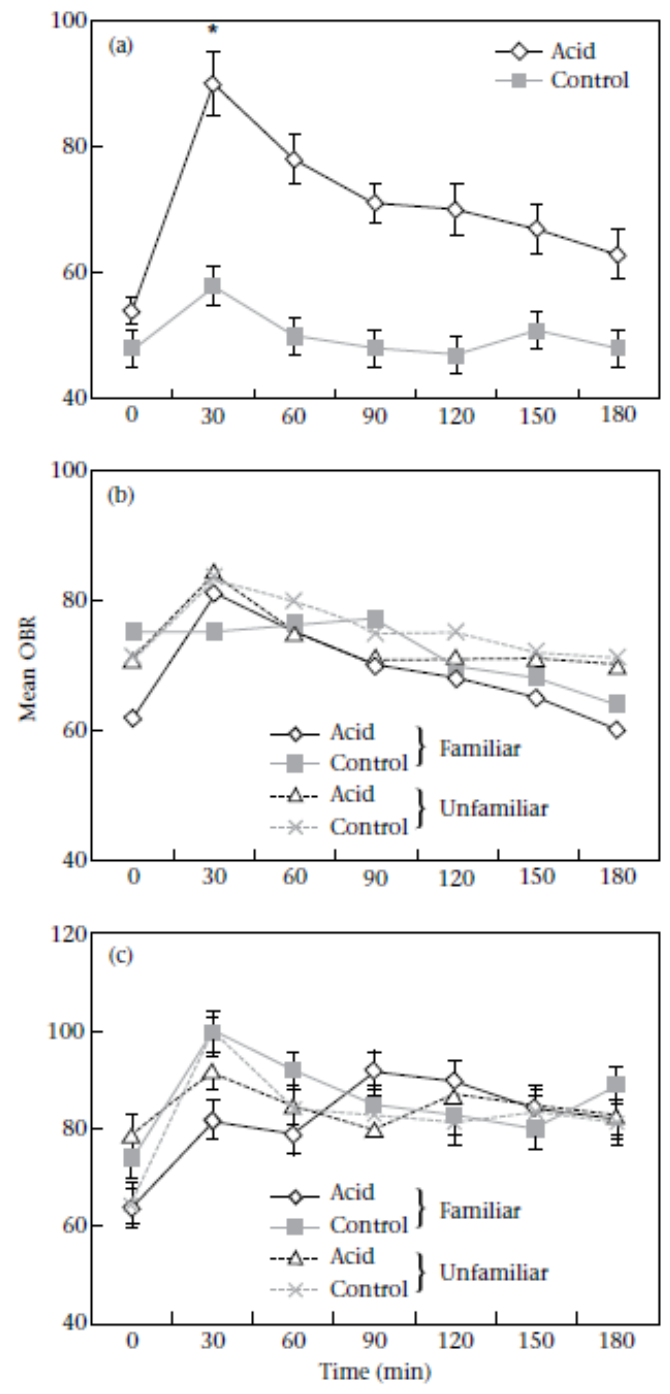
Figure 3. The effects of noxious stimulation on the dominant individual's aggressive strike rate (mean \pm SE per min) when returned to (a) a familiar or (b) an unfamiliar social group. The data are plotted over the experimental period at time 0 before treatment and at subsequent intervals after the treatment. ${ }^{*} \mathrm{P}<0.01 . \mathrm{N}=12$.

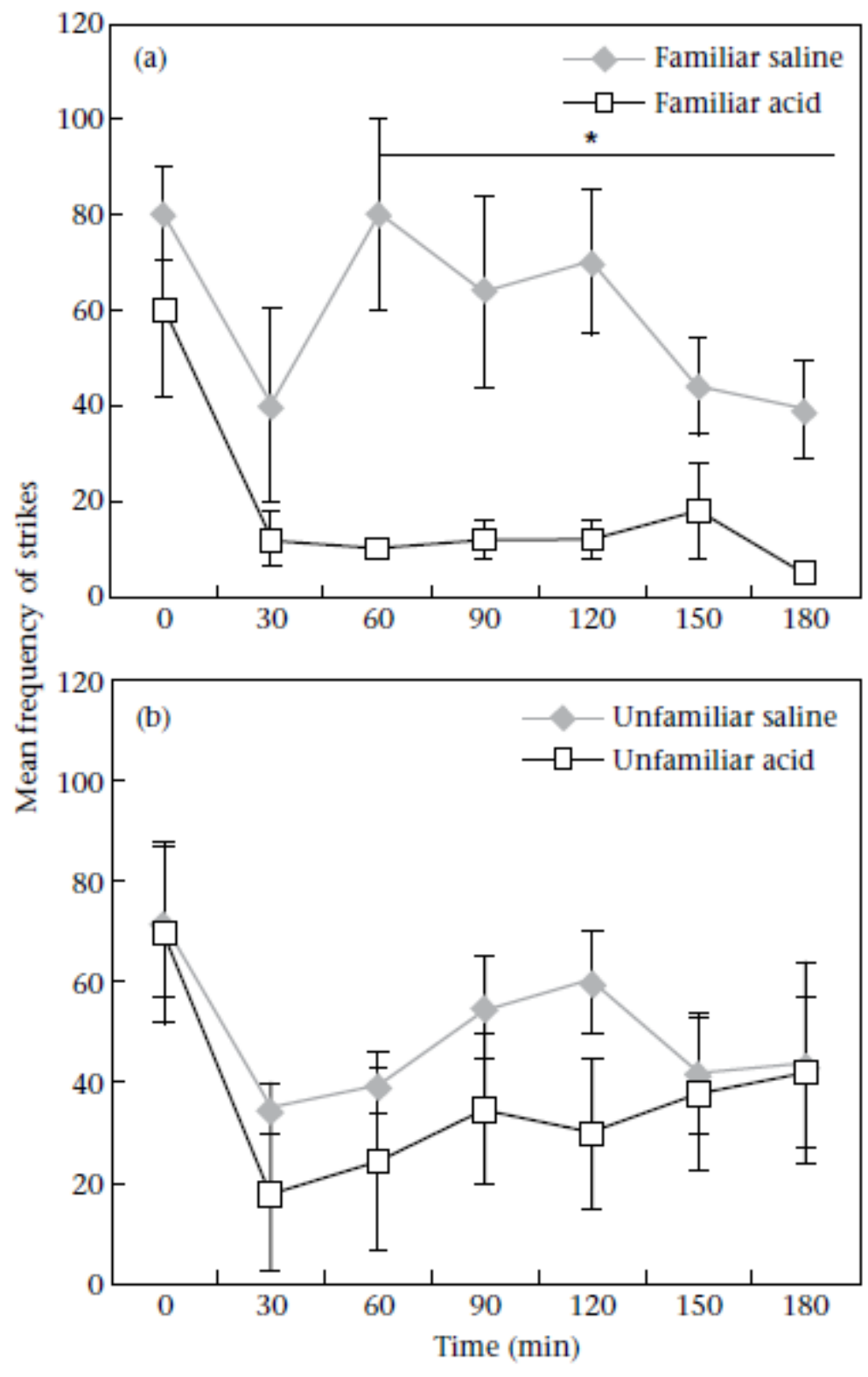

All groups reduced aggressive striking behaviour in the first observation immediately after the injection (Fig. 3a). When acid-treated dominants were returned to their familiar social group, there was a prolonged reduction in striking behaviour over the experimental period compared with controls but no comparable suspension of these aggressive strikes was seen when the treatment fish were returned to a novel social group, compared with controls $\left(F_{3,23}=12.75, P=0.030\right.$; unfamiliar acid group compared with three other groups: Tukey HSD: $\mathrm{P}=0.008$; Fig. $3 a, b)$. We observed no changes in behaviour in subordinates returned to either a familiar or an unfamiliar social group or between control and treatment (these fish did 
not perform aggressive strikes in any of the groups and their behaviour is passive as recorded in Sneddon et al. 2005).

Figure 4. Plasma cortisol concentrations for (a) individually held fish, (b) dominants and (c) subordinates returned to a familiar or unfamiliar social group. Mean values + SE are shown for (a) control and treatment individuals and (b, c) fish returned to a familiar group injected with saline (CF) or acid (TF) or to an unfamiliar group (saline: $\mathrm{CU}$; acid: $T U$ ) ${ }^{*}<0.05 . \mathrm{N}=6$ per group.
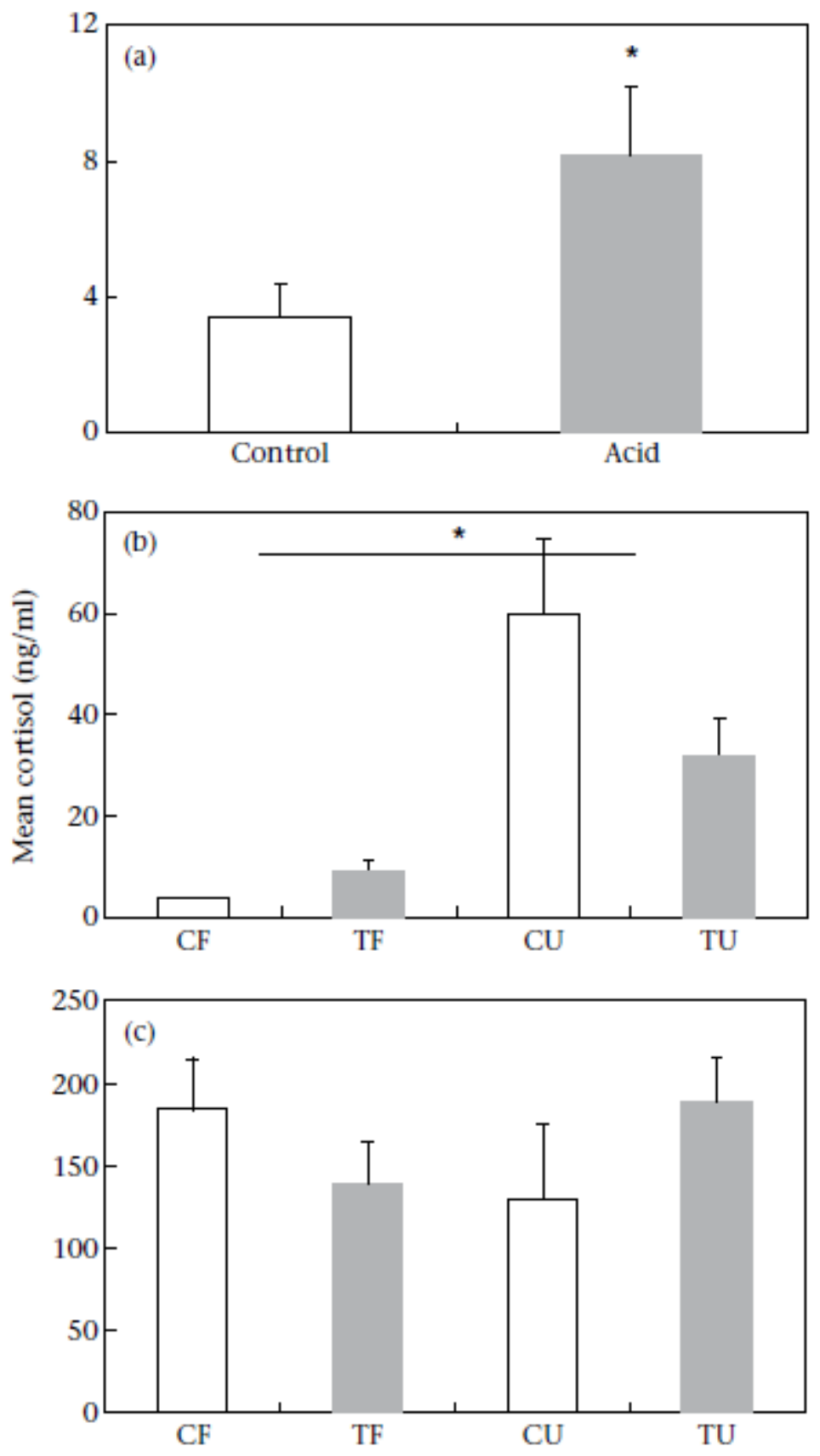

Plasma cortisol levels from noxiously stimulated trout held individually were significantly higher than in individually held controls $\left(t_{10}=2.53, \mathrm{P}=0.05\right.$; Fig. $\left.4 \mathrm{a}\right)$. However, there was no difference between control 
and treatment dominant fish returned to a familiar social group $\left(t_{10}=1.51, \mathrm{P}=0.65\right)$ or an unfamiliar social group ( $t_{10}=-0.57, P=0.30$; Fig. $\left.4 b\right)$. Overall, plasma cortisol levels were much higher in dominants returned to a unfamiliar group than a familiar one $\left(F_{1,19}=4.55, P=0.046\right)$. Subordinate fish had much higher levels of cortisol than dominant fish $\left(F_{1,46}=5.27, P=0.026\right)$, but there was no significant difference between control and treatment fish returned to a familiar $\left(t_{23}=0.66, \mathrm{P}=0.51\right)$ or unfamiliar group $\left(t_{23}=\right.$ $0.37, \mathrm{P}=0.71$; Fig. 4c).

\section{DISCUSSION}

We have demonstrated that rainbow trout were adversely affected both behaviourally and physiologically by exposure to a potentially painful event. In both experiments, the fish that were subjected to a noxious substance (acid) showed behavioural differences compared to their untreated conspecifics in response to alarm pheromone and when held individually or in familiar groups. When exposed to a predator cue, both bold and shy control fish increased their use of cover but also became more active, perhaps looking for an escape route. These antipredator responses have been measured in previous studies as a normal response to alarm pheromone (Magurran et al. 1996). No such responses were shown by the noxiously stimulated trout and bold fish even decreased their use of cover when the predator cue was presented. Control fish also showed a steady rise in OBR which suggests a fight or flight response, an antipredator physiological reaction, to prepare the animal for danger (Summers \& Winberg 2006). However, noxiously stimulated individuals showed a steady decline in OBR suggesting they were recovering from the noxious event which took precedence over showing an appropriate antipredator response. Similar findings for OBR have been reported for novel object testing of trout (Sneddon et al. 2003b) supporting the hypothesis that the potentially painful event is relatively more important than predator avoidance.

The results obtained from the alarm pheromone experiment are of ecological interest, as this substance is a predator cue that is produced naturally when the epidermis is damaged (Magurran et al. 1996). Other studies using alarm substances have described an increase in dashing or erratic behaviours, freezing or shelter use ('fright response'; Mathis \& Smith 1993). The control fish in this study showed similar behaviours to those described by Mathis \& Smith (1993) where increased time spent under cover and increased activity were seen to represent escape behaviour. The tanks we used to house the fish were relatively small and this could have affected the behaviour, as the fish were unable to escape to an area of the tank that was free of the alarm pheromone (cf. Brown \& Smith 1998). This may have increased the activity levels further, as the fish may have sought an escape route, explaining their increase in activity. The acid-treated group were less active and the bold fish used less cover in response to the predator cue, suggesting that the potentially painful event took priority such that they did not show an appropriate response. If fish behaved in this manner in a natural environment they would be at greater risk from predation. Our findings support the hypothesis that pain is an important stimulus or experience to the fish (Gentle 2001).

As well as the behavioural differences of acid-treated fish, there were also differences linked to the boldness of individuals. The bold trait has already been described as more active and aggressive and, therefore, more likely to occur in a dominant fish (Wilson et al. 1994; Sneddon 2003a; Frost et al. 2007). Acid-injected bold individuals doubled their activity after exposure to the alarm pheromone; however, they used cover less. This agrees with studies showing that bold fish are more willing to take risks in threatening situations (e.g. Wilson et al. 1994). Shy fish maintained their low activity levels in response to the alarm pheromone, confirming that they were more cautious and wary than bold fish (Frost et al. 2007). These findings suggest that following a painful event, shy fish may have better survivorship in the natural environment since bold fish used cover less and became more active and conspicuous. However, this remains to be tested. 
When held in social groups, noxiously stimulated fish did not show the physiological changes of individually held fish. There was no marked rise in OBR or in plasma cortisol relative to controls. In a familiar social setting, dominant fish reduced their aggressive behaviour suggesting that their motivation to maintain dominance was affected by the potentially painful event. In unfamiliar groups, however, no such behavioural impairment was seen and it would appear that exerting dominance over unfamiliar conspecifics does take priority over showing signs of pain. Dominance status confers a significant benefit with individuals at the top of the pecking order gaining preferential access to mates, shelter, territory and food (Gilmour et al. 2005) whereas subordinates can suffer high stress levels (Sloman et al. 2001).

The subordinate fish showed relatively little change in behaviour, and no change in activity, in response to noxious treatment or social grouping. Subordinate fish may generally suppress their behaviour to avoid provoking strikes by dominant or higher-ranked fish (Sneddon \& Yerbury 2003; Sneddon et al. 2006). This indicates that maintaining status and being the subordinate individual within a tank is of more importance than responding to pain, whether a stable hierarchy is present or not. Compared to the dominant fish, the subordinates showed even less pain-related behaviour; in fact only respiration rate was elevated in acid-treated fish returned to their home environment. Subordinate fish are generally inactive for most of the time, possibly in an attempt to avoid attack (Sneddon \& Yerbury 2003). When subordinate individuals are noxiously stimulated, there is thus little normal activity to alter in response, and again they may suppress any negative signs to prevent attack. This might occur to an even greater extent in a novel tank, where the subordinate fish will try to stay unnoticed, and even the respiration rate elevation is suppressed here.

An alternative explanation is suggested by the cortisol analysis of the plasma from individually held fish, the dominant groups and the subordinate treatment groups. The individual fish had the lowest plasma cortisol, followed by the dominants returned to a familiar group, dominants returned to an unfamiliar group and then the subordinates. Cortisol results in the release of endorphins and endogenous opioids that can act as painkillers within the central nervous system (Boccalon et al. 2006). This phenomenon is often termed stress-induced analgesia where a stressful situation results in a human or nonhuman animal not demonstrating signs of pain when injured (Davis 1979; Boccalon et al. 2006; Miranda et al. 2006). Since the subordinates had the highest cortisol level, they may also have had a high release of these endorphins and as such did not experience the painful stimulation and, therefore, showed no behavioural or physiological changes. This may also explain why the dominants returned to a novel social group did not show the reduction in aggression and thus were not behaviourally impaired as the dominants in their familiar group were. Stress-induced analgesia is seen in fish exposed to a stressful environment (L. U. Sneddon, K. L. Edwards, S. Ringrose, L. J. Oulton, P. J. Asklay \& C. R. McCrohan, unpublished data) and the opioid system in fish is similar to the mammalian system (Dreborg et al. 2008). Therefore, further work should be directed at understanding the differential responses of dominant and subordinate fish and linking this to social status.

This study has demonstrated that fish behaviour is altered by a noxious stimulus, including both normal antipredator responses and the number of aggressive strikes performed by a dominant fish in a familiar social group. Therefore, the potentially painful experience used in this study was shown to be important to the fish relative to predator cues and social situation. However, lower-ranked fish and dominants returned to a novel social situation were not visibly affected by pain. Social status is a significant factor in rainbow trout; dominant fish 'want' to maintain their dominance, while subordinate fish 'must avoid being attacked, and so remain passive to avoid attention. In this study, fish exposed to a painful stimulus showed little reaction to situations that, in a natural environment, would be potentially dangerous. This leads us to conclude that, under noxious stimulation, the fish's behaviour may be inappropriate in the context of predation. Our findings provide new evidence that fish are considerably affected by pain and that the 
perception is not just a simple nociceptive reflex. In light of this, there are welfare implications that need to be reconsidered with regard to the treatment of fish.

\section{Acknowledgments}

We are grateful to BBSRC (SS19809), UFAW (L.J.O) and the Wellcome Trust (E.W.) for funding and to Jon Banks, Ashley Frost, Helen Evans, Gregor Govan, Jess Mettam and Euan McLennan for technical assistance. We also thank Dr Tom Pottinger, CEH Lancaster, for conducting the cortisol assays and for comments on the manuscript along with Professor Alan Taylor, University of Glasgow.

\section{References}

Ashley, P. J., Sneddon, L. U. \& McCrohan, C. R. 2006. Properties of corneal receptors in a teleost fish. Neuroscience Letters, 410, 165-168.

Ashley, P. J., Sneddon, L. U. \& McCrohan, C. R. 2007. Nociception in fish: stimulus response properties of receptors on the head of trout Oncorhynchus mykiss. Brain Research, 1166, 47-54.

Boccalon, S., Scaggiante, B. \& Perissin, L. 2006. Anxiety, stress and nociceptive responses in mice. Life Sciences, 78, 1225-1230.

Brown, G. E. 2003. Learning about danger: chemical alarm cues and local risk assessment in prey fishes. Fish and Fisheries, 4, 227-234.

Brown, G. E. \& Smith, R. J. F. 1998. Acquired predator recognition in juvenile rainbow trout (Oncorhynchus mykiss): conditioning hatchery-reared fish to recognize chemical cues of a predator. Canadian Journal of Fisheries and Aquatic Science, 55, 611-617.

Chandroo, K. P., Duncan, I. J. H. \& Moccia, R. D. 2004. Can fish suffer: perspectives on sentience, pain, fear and stress. Applied Animal Behavior Science, 86, 225-250.

Davis, M. 1979. Conditioned fear-induced opiate analgesia: a competing motivational state theory of stress-induced analgesia. Annals of the New York Academy of Science, 467, 40-54.

Del Seppia, C., Mezzasalma, L., Chloeris, E., Luschi, P. \& Ghione, S. 2003. Effects of magnetic field exposure on open field behaviour and nociceptive responses in mice. Behavioral Brain Research, 144, 1-9.

Dreborg, S., Sundstrom, G., Larsson, T. A. \& Larhammer, D. 2008. Evolution of vertebrate opioid receptors. Proceedings of the National Academy of Sciences. U.S.A., 105 (40), 15487.

Dunlop, R. \& Laming, P. 2005. Mechanoreceptive and nociceptive responses in the central nervous system of goldfish (Carassius auratus) and trout (Oncorhynchus mykiss). Journal of Pain, 6, 561568.

Eccleston, C. 1995. Chronic pain and distraction: an experimental investigation into the role of sustained and shifting attention in the processing of chronic persistent pain. Behavioral Research Therapy, 33, 391-405.

Flecknell, P. A. \& Roughan, J. V. 2004. Assessing pain in animals: putting research into practice. Animal Welfare, 13, S71-S75. 
Frost, A. J., Ashley, P. J., Winrow-Giffen, A. \& Sneddon, L. U. 2007. Plasticity in animal personality traits: does prior experience alter the degree of boldness? Proceedings of the Royal Society of London, Series B, 274, 333-339.

Geerse, G. J., van Gurp, L. C. A., Wiegant, V. M. \& Stam, R. 2006. Individual reactivity to the open-field predicts the expression of cardiovascular and behavioural sensitisation to novel stress. Behavioral Brain Research, 175, 9-17.

Gentle, M. J. 2001. Attentional shifts alter pain perception in the chicken. Animal Welfare, 10, S187S194.

Gentle, M. J. \& Corr, S. A. 1995. Endogenous analgesia in the chicken. Neuroscience Letters, 201, 211214.

Gentle, M. J. \& Tilston, V. L. 1999. Reduction in peripheral inflammation by changes in attention. Physiology and Behavior, 66, 289-292.

Gilmour, K. M., DiBattista, J. D. \& Thomas, J. B. 2005. Physiological causes and consequences of social status in salmonid fish. Integrative and Comparative Biology, 45, 263-273.

Hamamoto, D. T., Forkey, M. W., Davis, W. L., Kajander, K. C. \& Simone, D. A. 2000. The role of pH and osmolarity in evoking the acetic acid-induced wiping response in a model of nociception in frogs. Brain Research, 862, 217-229.

Harris, J. A. \& Westbrook, R. F. 1994. Effects of midazolam and naloxone in rats tested for sensitivity/reactivity to formalin pain in a familiar, novel or aversively conditioned environment. Psychopharmacology, 115, 65-72.

Hoglund, E., Sorensen, C., Bakke, M. J., Nilsson, G. E. \& Overli, O. 2007. Attenuation of stress-induced anorexia in brown trout (Salmo trutta) by pre-treatment with dietary L-tryptophan. British Journal of Nutrition, 97, 786-789.

Kavaliers, M. \& Colwell, D. D. 1991. Sex-differences in opioid and non-opioid mediated predator-induced analgesia in mice. Brain Research, 568, 173-177.

Kavaliers, M. \& Colwell, D. D. 1994. Parasite infection attenuates non-opioid mediated predator-induced analgesia in mice. Physiology and Behavior, 55, 505-510.

Kuhajda, M. C., Thorn, B. E., Klinger, M. R. \& Rubin, N. J. 2002. The effect of headache pain on attention (encoding) and memory (recognition). Pain, 97, 213-221.

Lester, L. S. \& Fanselow, M. S. 1985. Exposure to a cat produces opioid analgesia in rats. Behavioral Neuroscience, 99, 756-759.

Machin, K. L. 2005. Avian pain: physiology and evaluation. Compendium of Continuing Education for the Practicing Veterinarian, 27, 98.

Magurran, A. E., Irving, P. W. \& Henderson, P. A. 1996. Is there a fish alarm pheromone? A wild study and critique. Proceedings of the Royal Society of London, Series B, 263, 1551-1556. 
Mathis, A. \& Smith, R. J. F. 1993. Fathead minnows, Pimephales promelas, learn to recognize northern pike, Esox lucius, as predators on the basis of chemical stimuli from minnows in the pike's diet. Animal Behaviour, 46, 645-656.

Miranda, A., De La Cruz, F. \& Zamudio, S. R. 2006. Immobility response elicited by clamping the neck induces antinociception in a 'tonic pain' test in mice. Life Science, 79, 1108-1113.

Mirza, R. S. \& Chivers, D. P. 2003. Response of juvenile rainbow trout to varying concentrations of chemical alarm cue: response thresholds and survival during encounters with predators. Canadian Journal of Zoology, 81, 88-95.

Moseley, G. L. \& Arntz, A. 2007. The context of a noxious stimulus affects the pain it evokes. Pain, 133, 64-71.

Nakama-Kitamura, M. \& Doe, N. 2003. The influence of contextual cue on anti-nociceptive tolerance and facilitation of memory with morphine. Journal of Pharmacological Science, 92, 237-244.

Pickering, A. D., Pottinger, T. G. \& Sumpter, J. P. 1987. On the use of dexamethasone to block the pituitary-interrenal axis in the brown trout, Salmo trutta L. General and Comparative Endocrinology, 65, 346-353.

Reilly, S. C., Quinn, J. P., Cossins, A. R.\&Sneddon, L. U. 2008a. Novel candidate genes identified in the brain during nociception in common carp (Cyprinus carpio) and rainbow trout (Oncorhynchus mykiss). Neuroscience Letters, 437, 135-138.

Reilly, S. C., Quinn, J. P., Cossins, A. R. \& Sneddon, L. U. 2008b. Behavioural analysis of a nociceptive event in fish: comparisons between three species demonstrate specific responses. Applied Animal Behaviour Science, 114, 248-259.

Scheurer, J. A., Berejikian, B. A., Thrower, F. P., Ammann, E. R. \& Flagg, T. A. 2007. Innate predator recognition and fright response in related populations of Oncorhynchus mykiss under different predation pressure. Journal of Fish Biology, 70, 1057-1069.

Scott, G. R., Sloman, K. A., Rouleau, C. \& Wood, C. M. 2003. Cadmium disrupts behavioural and physiological responses to alarm substance in juvenile rainbow trout (Oncorhynchus mykiss). Journal of Experimental Biology, 206, 1779-1790.

Sloman, K. A., Metcalfe, N. B., Taylor, A. C. \& Gilmour, K. M. 2001. Plasma cortisol concentrations before and after social stress in rainbow trout and brown trout. Physiological and Biochemical Zoology, 74, 383-389.

Smith, M. A., Bryant, P. A. \& McClean, J. M. 2003. Social and environmental enrichment enhances sensitivity to the effects of kappa opioids: studies on antinociception, diuresis and conditioned place preference. Pharmacology, Biochemistry and Behavior, 76, 93-101.

Sneddon, L. U. 2002. Anatomical and electrophysiological analysis of the trigeminal nerve of the rainbowtrout, Oncorhynchusmykiss. Neuroscience Letters, 312, 167-171.

Sneddon, L. U. 2003a. Trigeminal somatosensory innervation of the head of the rainbow trout with particular reference to nociception. Brain Research, 972, 44-52. 
Sneddon, L. U. 2003b. The evidence for pain perception in fish: the use of morphine as an analgesic. Applied Animal Behaviour Science, 83, 153-162.

Sneddon, L. U. 2003c. The bold and the shy: individual differences in rainbow trout. Journal of Fish Biology, 62, 971-975.

Sneddon, L. U. \& Yerbury, J. 2003. Differences in response to hypoxia in the three-spined stickleback from lotic and lentic localities: dominance and an anaerobic metabolite. Journal of Fish Biology, 64, 799-804.

Sneddon, L. U., Braithwaite, V. A. \& Gentle, M. J. 2003a. Do fish have nociceptors: evidence for the evolution of a vertebrate sensory system. Proceedings of the Royal Society of London, Series B, 270, 1115-1122.

Sneddon, L. U., Braithwaite, V. A. \& Gentle, M. J. 2003b. Novel object test: examining pain and fear in the rainbow trout. Journal of Pain, 4, 431-440.

Sneddon, L. U., Margareto, J. \& Cossins, A. R. 2005. The use of transcriptomics to address questions in behaviour: production of a suppression subtractive hybridisation library from dominance hierarchies of rainbow trout. Physiological and Biochemical Zoology, 78, 695-705.

Sneddon, L. U., Hawkesworth, S., Braithwaite, V. A. \& Yerbury, J. 2006. Impact of environmental disturbance on the stability and benefits of individual status within dominance hierarchies. Ethology, 112, 437-447.

Summers, C. H. \& Winberg, S. 2006. Interactions between the neural regulation of stress and aggression. Journal of Experimental Biology, 209, 4581-4589.

Willenbring, S. \& Stevens, C. W. 1995. Thermal, mechanical and chemical peripheral sensation in amphibians: opioid and adrenergic effects. Life Sciences, 58, 125-133.

Wilson, D. S., Coleman, K., Clark, A. B. \& Biederman, L. 1993. Shy bold continuum in pumpkinseed sunfish (Lepomis gibbosus): an ecological study of a psychological trait. Journal of Comparative Psychology, 107, 250-260.

Wilson, D. S., Clark, A. B., Coleman, K. \& Dearstyne, T. 1994. Shyness and boldness in humans and other animals. Trends in Ecology \& Evolution, 9, 442-446.

Zhao, X. X., Ferrari, M. C. O. \& Chivers, D. P. 2006. Threat-sensitive learning of predator odours by a prey fish. Behavior, 143, 1103-1121. 